\title{
Introducing Systems \\ Design
}

NeC

西 


\section{Introducing Systems \\ Design}

Second Edition

Steve Skidmore

NCC Macmillan Education 
Copyright $\mathbb{C}$ S. R. Skidmore, 1989, 1996

The right of Steve Skidmore to be identified as author of this work has been asserted in accordance with the Copyright, Designs and Patents Act 1988.

First published 1989

First published in USA 1989

Second edition 1996

Second edition published in USA 1996

$\begin{array}{llllllllll}2 & 4 & 6 & 8 & 10 & 9 & 7 & 5 & 3 & 1\end{array}$

NCC Blackwell

108 Cowley Road

Oxford OX4 1JF

UK

Blackwell Publishers Inc.

238 Main Street

Cambridge, Massachusetts 02142

USA

All rights reserved. Except for the quotation of short passages for the purposes of criticism and review, no part of this publication may be reproduced, stored in a retrieval system, or transmitted, in any form or by any means, electronic, mechanical, photocopying, recording or otherwise, without the prior permission of the publisher.

Except in the United States of America, this book is sold subject to the condition that it shall not, by way of trade or otherwise, be lent, resold, hired out, or otherwise circulated without the publisher's prior consent in any form of binding or cover other than that in which it is published and without a similar condition including this condition being imposed on the subsequent purchaser.

British Library Cataloguing in Publication Data

A CIP catalogue record for this book is available from the British Library.

Library of Congress Cataloging-in-Publication Data

Skidmore, Steve.

Introducing systems design/Steve Skidmore.

Cambridge, Mass. : NCC Blackwell, 1996.

p. $\mathbf{c m}$.

QA76.9.S88 $\quad$ S59 1996

005.1/2 20

1855542471 (pbk. : alk. paper)

Includes index.

Systems design.

95047493

ISBN 978-0-333-72140-7

ISBN 978-1-349-25536-8 (eBook)

DOI 10.1007/978-1-349-25536-8

Typeset in 10 on 12pt Caledonia and Frutiger

This book is printed on acid-free paper 


\section{Contents}

$\begin{array}{ll}\text { Preface } & \text { ix }\end{array}$

1 Context 1

1.1 Introduction

1.2 Structure of the book

1.3 Objectives of design

1.4 Constraints on design

1.5 The products of analysis

1.6 CASE tools

1.7 Summary

2 Input and Output Design

2.1 Introduction

2.2 The design boundary

2.3 Output contents

2.4 Output technology

2.5 Detailed output design

2.6 Input design

2.7 Input design guidelines

2.8 Input technologies

2.9 Summary

3 Designing Interfaces

3.1 Introduction

3.2 Dialogue types

3.3 Logical dialogue outline

3.4 Input/output structures

3.5 State transition diagrams

3.6 Summary 


\section{vi Contents}

4 Rapid Application Development

4.1 Introduction

4.2 Prototyping: meaning and procedure

4.3 Prototype construction

4.4 Prototyping assessed

4.5 The development team

4.6 Summary

5 Logical Data Design

5.1 Introduction

5.2 Basic concepts and terminology

5.3 Bottom-up normalization

5.4 Logical data model

5.5 Conclusion

6 Logical Process Design

6.1 Introduction

6.2 Structured English

6.3 Action Diagrams

6.4 Extended action diagramming conventions (ADAPT)

6.5 SSADM Version 4: update process specification

6.6 Logical Access Maps

6.7 Conclusion

7 Object-oriented Design

7.1 Introduction

7.2 Object-oriented analysis

7.3 Object notation and constructs

7.4 Object principles

7.5 Modelling object behaviour

7.6 Summary

8 Physical Design

8.1 Introduction

8.2 Logical and physical data design

8.3 Optimizing using facilities of the hardware and software

8.4 Optimizing by tuning the logical model

8.5 Implications for data base design

8.6 Data and process design

8.7 Physical process design

8.8 Summary 
9 Systems Controls

138

9.1 Introduction

9.2 Areas of risk

9.3 Systems controls

9.4 The auditing function

9.5 Legal requirements

9.6 Summary

10 System Implementation

10.1 Introduction

10.2 Testing

10.3 File conversion

10.4 Preparation of documentation

10.5 Training

10.6 Implementation strategies

10.7 Post-implementation review

10.8 Conclusion

11 Systems Development

166

11.1 Introduction

11.2 Objectives of design: reviewed

11.3 Review of methodology

Appendices

173

A: InfoSys case study

B: Further reading

C: Exercises

Index 


\section{Preface}

This book is the second of two texts about the development of computer systems. It presents a series of models and skills that should help the definition and delivery of high-quality information systems. This book is primarily concerned with logical and physical design.

The book is primarily aimed at:

- undergraduate and Higher National Diploma and Certificate students undertaking a module in systems analysis and design;

- students undertaking professional examinations;

- trainee analysts studying for professional qualifications or following professional development schemes;

- practising systems designers and developers.

Analysis and Design are two words in common currency in systems development. The preface to the companion text makes the point that the distinction is arbitrary and that analysis, design and development is used interchangeably throughout the text to provide some variety. However, it is worth highlighting how the content and split of the two books has been determined.

Introducing Systems Analysis is primarily about analysing business benefits and procedures. The Data Flow Diagram is introduced as a technique for modelling understanding of current systems and developing an overall functional architecture for fulfilling agreed requirements. Data Flow Diagrams are not well suited to design but they are an effective analysis model. The Logical Data Structure is also an effective architectural model, expressing the structure and size of systems more effectively than text. In our company we construct these models as part of our estimating process. The inclusion of Entity Life Histories in an analysis text is probably more controversial. However, we find that they do highlight facets of the system not illuminated by the other two models. Furthermore, they provide an introduction to an object perspective as well as a basis for later detailed design.

The content of the two books is also determined by what we feel comfortable in presenting in two one-week courses to practitioners. The material of both books 


\section{x Preface}

can be comfortably covered in around 35-40 hours of study. Delegates usually take a break between the two courses to allow some time for reflection and relaxation! This duration also fits in (supported by exercises and assignments) with what inexperienced developers can accomplish in an academic term, semester or year depending upon the number of hours per week allocated to lecturers and tutorials.

I hope readers find this a practical introduction. In our own company (the 'we' of the text) I sit with other developers using, extending and selecting the tools and techniques covered here. This experience has forged the way I look at things and I would like to acknowledge their contribution. I have also spent a considerable amount of time explaining and exploring these models with users (in our software development projects) and delegates (on our training courses). Many have suggested changes and clarifications to the models, some of which have found their way into the two books in this series.

Finally, I would like to specifically acknowledge the following people who have helped my understanding of systems development and its teaching-Mike Crawford, Brenda Wroe, Gillian Mills, Andrew Parkin, David Helmy, David Howe, Ray Farmer, Frank Land and Ron Stamper.

Steve Skidmore 